\title{
Roughness Control of Layer-by-Layer and Alternative Spray Films from Congo Red and PAH via Laser Light Irradiation
}

\author{
Gleidson Cardoso, Romário J. da Silva, Rafael R. G. Maciel, Nara C. de Souza, Josmary R. Silva
}

Grupo de Materiais Nanoestruturados, Universidade Federal de Mato Grosso, Barra do Garças, Brazil.

Email: josmarysilva@ufmt.br

Received May $10^{\text {th }}, 2012$; revised June $17^{\text {th }}, 2012$; accepted July $12^{\text {th }}, 2012$

\begin{abstract}
Films from congo red (CR) alternated with poly(allylamine hydrochloride), PAH, were prepared by layer-by-layer and alternative spray techniques. In order to investigate the change of roughness induced by laser light irradiation (532 $\mathrm{nm})$, both kinds of films were characterized by using UV-visible spectroscopy and atomic force microscopy (AFM). At different irradiation times, layer-by-layer, LbL, films showed small changes in the roughness and irregular behavior, whereas spray films exhibited higher and a regular decreasing of roughness with increasing irradiation time. The higher roughness of spray films as compared with the LbL ones was attributed to different formation mechanisms of the films. The decreasing of the roughness as a function of the irradiation time (exhibited by the spray films) was associated to surface relaxation due to the interplay between photoisomerization of congo red dye and the heating of the sample during the laser light irradiation. The results suggested that the alternative spray technique is the best choose to control of roughness of the films by using light irradiation.
\end{abstract}

Keywords: Congo Red; Poly(Allylamine Hydrochloride); Layer-by-Layer Films; Roughness Control; Laser Light Irradiation

\section{Introduction}

Molecules able to exhibit geometric isomerization (change of geometric shape in space) by the action of light, such as azobenzene and their derivatives are promising because they have characteristics suitable for application in memory devices, optical switches and modulators [1]. Moreover, they make an important role in processes at the nanoscale transduction of biological signals [2]. Azobenzene derivate compounds have been widely studied for their trans-cis-trans photoisomerization property, which may lead to optical storage and formation of surface-relief grades. When azobenzene derivated molecules are excited from conformational state trans to cis by the action of light, and then returned to the state trans $[3,4]$, they adopt the orientation in which its electric dipole moment is perpendicular to the direction of polarization light. Because of this, after some time of light irradiation, which occur during the trans photoisomerization cycles trans $\rightarrow$ cis $\rightarrow$ trans, comes an excess of molecules oriented perpendicular to the axis of the dipole electric field optical excitation, providing the optical birefringence and dichroism in films [4]. Another important property of azobenzene derivatives, which also comes from the molecular photoisomerization, is the change of surface morphology of films [5] producing surface relief grades. This process is among the most interesting effects associated with the photoisomerization $[1,6]$. Nanostructured films of azobenzene derivatives have been prepared by using various techniques, such as layer-by-layer [7], Langmuir-Blodgett [4], and spin-coating [8]. In special, the LbL technique is based on the spontaneous adsorption of charged species from a solution onto a solid substrate. The paradigm of LbL is the adsorption based on ionic interaction $[9,10]$. A technique proposed recently is the spray self-assembly introduced by Decher et al. [11]. In this technique, layers of material are alternated by spraying their solutions by controlled time [12].

Despite several studies on films of derivatives of azobenzene, we are not aware of any comparison of the effect of laser irradiation on LbL and simple spray films. In this work we have proposed an alternative, very simple and low cost spray technique. We have investigated the effect of laser irradiation on roughness of layerby-layer and films prepared by alternative spray technique, alternating poly (allylamine hydrochloride), PAH, and congo red dye, CR. We have noted that the LbL 
films exhibited lower roughness than the spray ones; however, the spray showed more regular change behavior of roughness as a function of light irradiation and, consequently, allowed a good roughness control.

\section{Materials and Methods}

Films were adsorbed on BK7 optical glass slides $(36 \mathrm{~mm}$ $\times 14 \mathrm{~mm} \times 1 \mathrm{~mm}$ ), which were rendered hydrophilic in a 3:7 mixture of hydrogen peroxide $\left(\mathrm{H}_{2} \mathrm{O}_{2}\right)$ /concentrated sulfuric acid $\left(\mathrm{H}_{2} \mathrm{SO}_{4}\right)$. The slides were rinsed and then further cleaned in a solution containing pure water, $\mathrm{H}_{2} \mathrm{O}_{2}$, and ammonium hydroxide $\left(\mathrm{NH}_{4} \mathrm{OH}\right)$ in a ratio of $5: 1: 1$ $(\mathrm{v} / \mathrm{v})$. BK7 slides were chosen because of its negligible absorbance in the visible region and its finely polished surface [13]. Congo red (CR) and poly(allylamine hydrochloride) (PAH) were purchased from AMRESCO Inc. and Sigma-Aldrich, respectively. Layer-by-layer films were assembled by the alternated immersion of the BK7 substrate in the PAH and CR solutions for 3 min each at room temperature. After each deposition step, the formed layer was drying under an air flow. The concentration of the dipping solutions (CR and PAH) for the films preparation was set at $0.5 \mathrm{~g} / \mathrm{L}$ and the $\mathrm{pH}$ was adjusted to 8 to the solutions of $\mathrm{CR}$ (adding $\mathrm{NH}_{4} \mathrm{OH}$ ) and 4 to the solutions of PAH by adding $\mathrm{HCl}$.

\subsection{Alternative Spray Technique}

Alternative spray films were fabricated by using simple glass flasks, such as small fragrance bottle, with volume capacity of $10 \mathrm{~mL}$, as showed in Figure 1. The BK7 substrate was kept vertically and perpendicular to the spray flux. The waiting time for drying between one layer and the next one was $5 \mathrm{~min}$. The spray droplets from the slip surface by gravitational effect forming a thin film.

In order to achieve uniformity in wetting of the surface with the flasks used to prepare the spray films, it was performed a plot of average diameter of wetting area as a function of distance between spray nozzle and film surface, as shown in Figure 1(b). From this result, it was fixed $5 \mathrm{~cm}$ in distance for all experiments.

\subsection{Characterization}

The growth of LbL and alternative spray films were monitored using UV-visible spectroscopy with a Thermolab Genesys 10 spectrophotometer. The surface morphology of the films was studied with a NanoSurf Instruments atomic force microscope EasyScan II in the tapping mode $(256 \times 256$ pixels $)$, under ambient conditions. A sample area of $40 \mu \mathrm{m} \times 40 \mu \mathrm{m}$ was scanned and an image was acquired. The film roughnesses were determined using NanoSurf Instruments software. Irradiations of films were carried out by impinging a linearly polarized laser beam at $532 \mathrm{~nm}$ from a diode laser (BW \& Tek Inc.). The used power was $5.0 \mathrm{~mW}$ with a spot of ca. $1.8 \mathrm{~mm}$ in diameter.

\section{Results and Discussion}

The CR molecules absorb in the visible region, which makes the UV-vis spectroscopy technique a powerful tool in the investigation of adsorption kinetics during the growth of films. Figure 2 shows an inset with the spectra of CR solution and PAH/CR LbL and alternative spray films. The spectra found in our study are essentially the same as those found in the literature for the CR [14]. There is not observed spectrum shift as the solid phase UV-vis is compared to spectra of the solution phase,

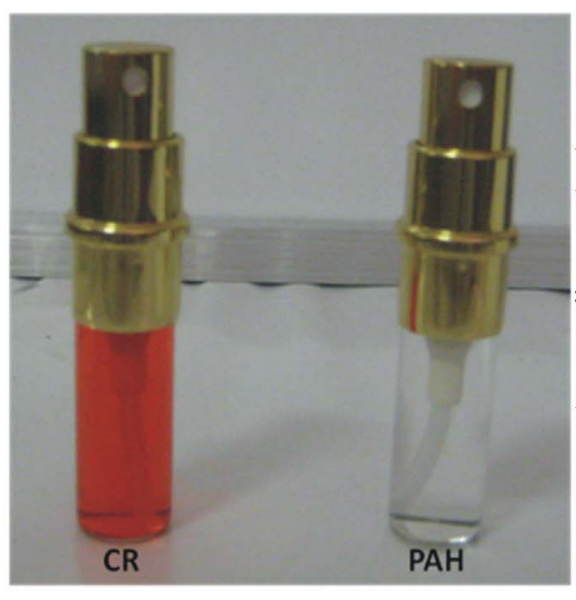

(a)

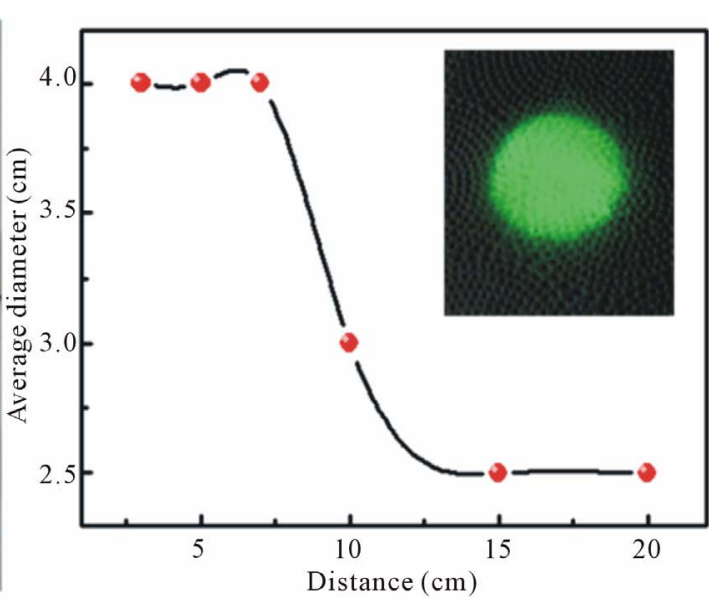

(b)

Figure 1. (a) Glass flasks used to prepare the spray films and (b) plot of average diameter of wetting spot as a function of distance between spray nozzle and film surface. The inset (negative photo) depicts a complete wetting area. The solid line is a guide to the eyes. 


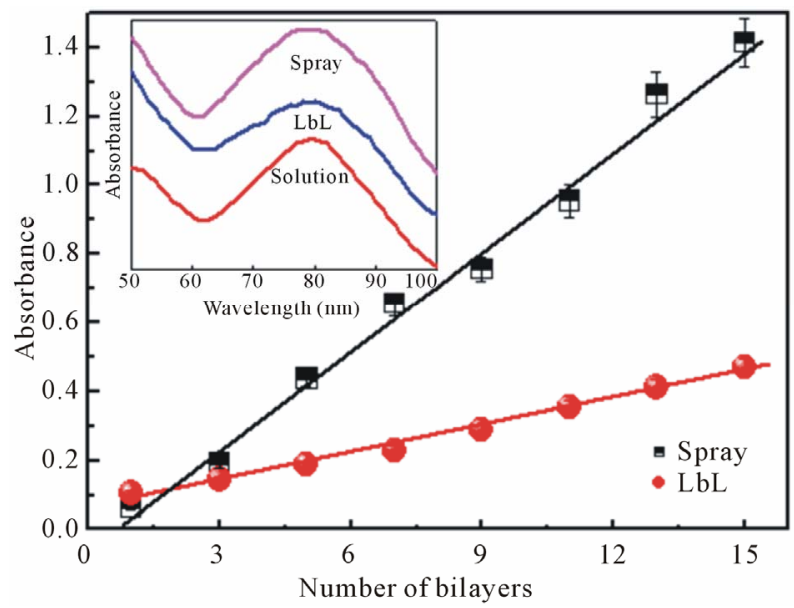

Figure 2. Absorbance at $500 \mathrm{~nm}$ versus number of bilayers for PAH/CR LbL and cycles of alternative spray films onto BK7 glass. The solid line is just a guide for the eyes. The inset shows the spectra of CR solution and CR alternated with PAH on films form.

indicating that the molecular $\mathrm{H}$ or J-aggregation does not occur for these systems [15].

As shown in Figure 2, a linear increase in the absorbance at $500 \mathrm{~nm}$ was observed, suggesting that the same amount of material was adsorbed in each deposition step (each layer). Moreover, the linear film growth of the first bilayer indicates that for this kind of LbL or alternative spray films, the influence of the substrate on the growth film is negligible $[13,16]$. The absorbance is proportional to the amount adsorbed [16] and a direct comparison between the techniques shows that although the growth of film is approximately linear for both, the film obtained with the alternative spray technique grows more rapidly than that obtained by the conventional LbL technique (Figure 2). So, this technique can provide thicker films with less cycles of deposition. This can be interesting for some applications that require a more effective coating, such as surface relief gratings.

Figure 3 shows AFM images of 15-bilayer LbL films and 15 complete cycles of alternative spray films from $\mathrm{PAH} / \mathrm{CR}$ in which the top layer is $\mathrm{CR}$. The images were taken in a scan window of $40 \mu \mathrm{m} \times 40 \mu \mathrm{m}$. A clear structure rod-shaped lying on the surface can be identified in the analysis of morphology [17-20]. This kind of structures in spray films is larger than that of LbL films. The surface morphology of alternative spray films change when the films are irradiated, while the change is less observable in LbL films. This change can be more easily observed in Figure 4 that shows how the roughness changes when the LbL or alternative spray films are irradiated for different times. For LbL films the roughness remains about $80 \mathrm{~nm}$, whereas for alternative spray films, the roughness decreases with irradiation time
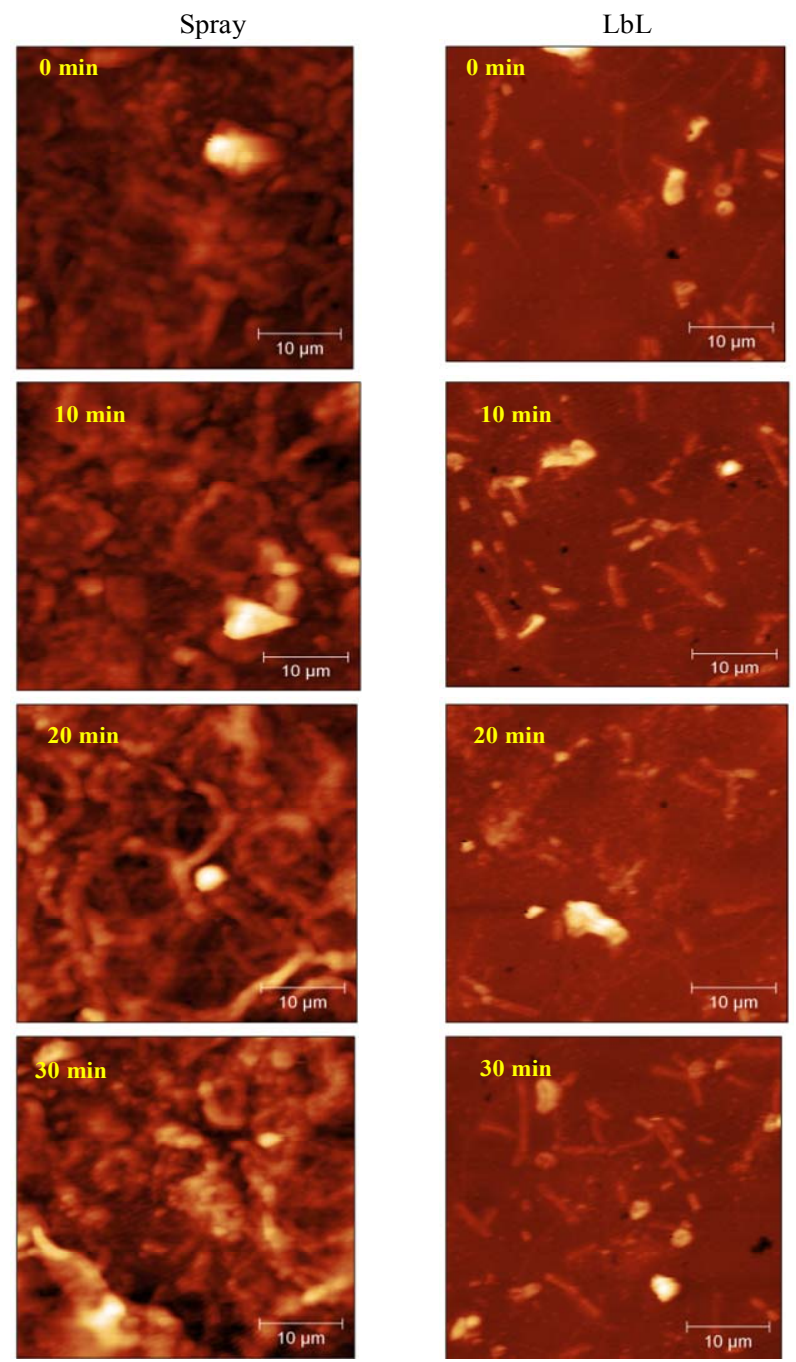

Figure 3. AFM images of $P A H / C R$ alternative spray and LbL films with $C R$ atop. The images were taken with a scan window of $40 \mu \mathrm{m} \times 40 \mu \mathrm{m}$. The surface morphology was investigated as a function of the irradiation time.

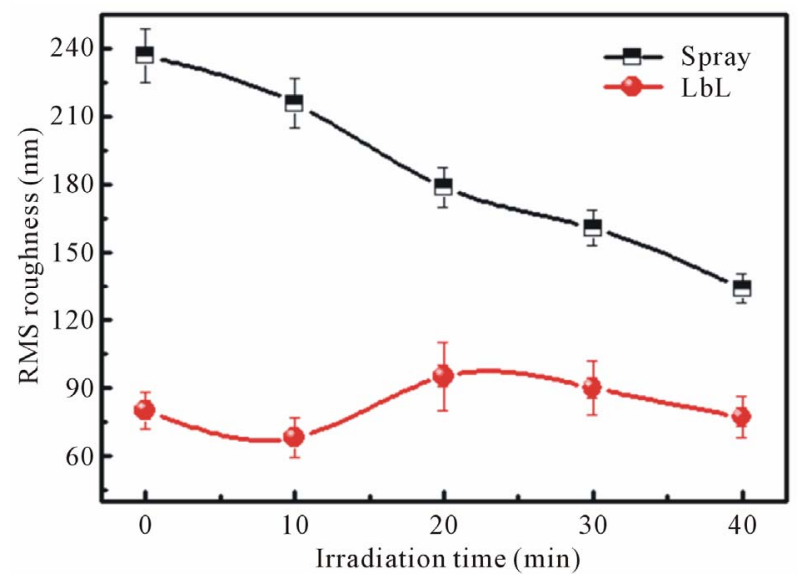

Figure 4. Roughness vs. irradiation times for the PAH/CR LbL and alternative spray films. 
about $50 \%$.

The large difference in roughness between the LbL and spray films can be explained by considering the formation process of each kind of film. LbL films are formed by the spontaneous adsorption of molecules from solution onto the substrate [9] or PAH layer that is accompanied of drying process, whereas in the alternative spray films, a large amount of molecules staying in contact for more time during the drying process $(5 \mathrm{~min}$ for each layer). Decher showed that the thickness increase as function of time [11].

In addition LbL films have a smaller roughness and a more stable structure under irradiation because of the spontaneous adsorption of molecules which produces a higher molecular packing. In the case of alternative spray films, the lower packing concert with the higher roughness becomes possible controlling the roughness through the laser irradiation. This can occur though relaxing of the surface structure caused by the interplay between photoisomerization and heating of the films.

\section{Conclusion}

Layer-by-layer and alternative spray films were successfully prepared from congo red dye alternated with PAH. The comparison between the two systems revealed that the roughness of the LbL films is smaller than those exhibited by the spray ones. This was attributed to difference in structure of the two kinds of films due to formation mechanisms. It was found that only the spray films displayed regular roughness changes of their surface under laser irradiation which was associated to lower packing concert with the higher roughness. These results suggested that this alternative spray technique provide films thicker and with higher roughness that may be a good alternative to $\mathrm{LbL}$ one when is required more material adsorbed and a roughness control for device applications.

\section{Acknowledgements}

This work was supported by CNPq and CAPES (Brazil). R. J. da Silva and R. R. G. Maciel thank Capes (nbioNet) and CNPq for the scholarship.

\section{REFERENCES}

[1] R. H. El Halabieh, O. Mermut and C. J. Barret, "Using Light to Control Physical Properties of Polymers and Surfaces with Azobenzene Chromophores," Pure and Applied Chemistry, Vol. 76, No. 7-8, 2004, pp. 1445-1465. doi:10.1351/pac200476071445

[2] G. Groenhof, M. F. Lensink, H. J. C. Berendsen, J. G. Snijders and A. E. Mark, "Signal Transduction in the Photoactive Yellow Protein. I. Photon Absorption and the
Isomerization of the Chromophore," Proteins: Structure, Function, and Genetics, Vol. 48, No. 2, 2002, pp. 202211. doi: $10.1002 /$ prot. 10136

[3] J. Yang, J. Y. Zhang, H. Liu, P. Wang, H. Ma, H. Ming, Z. C. Li and Q. J. Zhang, "Holographic Grating Recording in Azobenzene Polymer Films," Optical Materials, Vol. 27, No. 3, 2004, pp. 527-532. doi:10.1016/j.optmat.2004.04.013

[4] J. R. Silva, F. F. Dall'Agnol, N. C. de Souza, O. N. Oliveira and J. A. Giacometti, "Photoinduced Birefringence at Low Temperatures in Langmuir-Blodgett Films of Azobenzene-Functionalized Copolymers," Synthetic Metals, Vol. 138 No. 1-2, 2003, pp. 153-156. doi:10.1016/S0379-6779(02)01273-0

[5] J. R. Silva, N. C. Souza, D. S. dos Santos Jr., et al., "Morphology Changes Induced by Laser Irradiation on Disperse Red 13 Films Prepared by Physical Vapor Deposition," Synthetic Metals, Vol. 137, No. 1-3, 2003, pp. 1477-1478. doi:10.1016/S0379-6779(02)01196-7

[6] C. R. Mendonça, A. Dhanabalan, D. T. Balogh, et al., "Optically Induced Birefringence and Surface Relief Gratings in Composite Langmuir-Blodgett (LB) Films of Poly[4'-[[2-(Methacryloyloxy)Ethyl]Ethylamino]-2-Chlor o-4-Nitroazobenzene] (HPDR13) and Cadmium Stearate," Macromolecules, Vol. 32, No. 5, 1999, pp. 1493-1499. doi:10.1021/ma981644i

[7] Z. Sekkat, J. Wood, Y. Geerds, A. ElMeskini, M. Buchel and W. Knoll, "Organized Photochromic Azo-Polymeric Structures: Self-Assembled and Langmuir-Blodgett-Kuhn Layers," Synthetic Metals, Vol. 81, No. 2-3, 1996, pp. 281-285. doi:10.1016/S0379-6779(96)03739-3

[8] J. Meng, A. Natansohn and P. Rochon, "Azo Polymers for Reversible Optical Storage. 11 Poly $\{4,4$ '-(1-Methylethylidene)Bisphenylene 3-[4-(4-Nitrophenylazo)Phenyl]3-Aza-Pentanedioate\}," Journal of Polymer Science Part B: Polymer Physics, Vol. 34, 1996, pp. 1461-1466. DOI:10.1002/(SICI)1099-0488(199606)34:8<1461::AIDPOLB9>3.0.CO;2-V

[9] G. Decher, "Fuzzy Nanoassemblies: Toward Layered Polymeric Multicomposites," Science, Vol. 277, No. 5330, 1997, pp. 1232-1327. doi:10.1126/science.277.5330.1232

[10] Y. Wang, A. S. Angelatos and F. Caruso, "Template Synthesis of Nanostructured Materials via Layer-by-Layer Assembly," Materials Chemistry, Vol. 20, No. 3, 2008, pp. 848-858. doi: $10.1021 / \mathrm{cm} 7024813$

[11] A. Izquierdo, S. S. Ono, J. C. Voegel, P. Shaaf and G. Decher, "Dipping versus Spraying: Exploring the Deposition Conditions for Speeding Up Layer-by-Layer Assembly," Langmuir, Vol. 21, No. 16, 2005, pp. 75587567. doi: $10.1021 / \mathrm{la} 047407 \mathrm{~s}$

[12] K. C. Krogman, N. S. Zacharia, S. Schroeder and P. T. Hammond, "Automated Process for Improved Uniformity and Versatility of Layer-by-Layer Deposition,", Langmuir, Vol. 23, No. 6, 2007, pp. 3137-3141. doi: $10.1021 / \mathrm{la} 063085 \mathrm{~b}$

[13] N. C. de Souza, et al., "Influence of Solution Treatment on the Adsorption and Morphology of Poly(o-Methoxyaniline) Layer-by-Layer Films," The Journal of Physical 
Chemistry B, Vol. 108, No. 36, 2004, pp. 13599-13606. doi:10.1021/jp037873a

[14] T. E. Sladewski, A. M. Shafer and C. M. Hoag, "The Effect of Ionic Strength on the UV-Vis Spectrum of Congo Red in Aqueous Solution," Spectrochimica Acta Part A, Vol. 65, No. 3-4, 2006, pp. 985-987. doi:10.1016/j.saa.2006.02.003

[15] M. C. Petty, "Langmuir-Blodgett Films: An Introduction," Cambridge University Press, Cambridge, 1996. doi:10.1017/CBO9780511622519

[16] J. B. Brito, D. J. C. Gomes, V. D. Justina, A. M. F. Lima, C. A. Olivati, J. R. Silva and N. C. de Souza, "Nanostructured Films from Phthalocyanine and Carbon Nanotubes: Surface Morphology and Electrical Characterization," Journal of Colloid and Interface Science, Vol. 367, No. 1, 2012, pp. 467-471. doi:10.1016/j.jcis.2011.10.004

[17] A. L. Barabási and H. E. Stanley, "Fractal Concepts in
Surface Growth," Cambridge University Press, Cambridge, 1995

[18] R. C. Salvarezza, L. Vázquez, P. Herrasti, P. Ocón, J. M. Vara and A. J. Arvia, "Self-Affine Fractal Vapour-Deposited Gold Surfaces Characterization by Scanning Tunnelling Microscopy," Europhysics Letters, Vol. 20, No. 8, 1992, pp. 727-732. doi:10.1209/0295-5075/20/8/011

[19] P. Keblinski, A. Maritan, F. Toigo, R. Messier and J. R. Banavar, "Continuum Model for the Growth of Interfaces," Physical Review E, Vol. 53, No. 1, 1996, pp. 759-778. doi:10.1103/PhysRevE.53.759

[20] A. Mazor, D. J. Srolovitz, P. S. Hagan and B. G. Bukiet, "Columnar Growth in Thin Films," Physical Review Letters, Vol. 60, 1988, pp. 424-427. doi:10.1103/PhysRevLett.60.424 